\title{
Promoting EFL learners' exposure to multiculturalism using Skype in the classroom - a case study
}

\author{
Khang D. Nguyen*, Van T. T. Phan** \\ *Can Tho University, Vietnam; ndkhang@ctu.edu.vn \\ **Can Tho University, Vietnam; pttuyetvan@ctu.edu.vn
}

\begin{abstract}
The study aims at indicating the effectiveness of employing Skype in the classroom to promote chances for EFL learners to expose to multiculturalism. Action research was carried out via a one-year case study on a teacherparticipant. The data was collected by observation during Skype connections, the participant's reflections before and after the connections, and interview of the teacher-participant for his reflections for enhancing his learners' chances for acquiring multiculturalism. The findings of the study showed that Skype benefited the teacherparticipant in facilitating multiculturalism in EFL learning contexts, how Skype could be useful for multicultural connections, and the development of learners' common curiosity about other cultures through the exposure to multiculturalism.
\end{abstract}

Keywords: multiculturalism, Skype in the classroom, language teaching and learning

\section{Introduction}

Being exposed to the multicultural learning environment in Europe for a few years has actually been a chance for any EFL teachers to be aware of the benefits, diversities, and possible problems during the fast era of globalization and the $4^{\text {th }}$ generation of industrial development. The idea of showing how the world is different in other cultures is important and should be noticed to EFL learners in this context. Several reasons for the quest of promoting more learners' exposure to multiculturalism should be implemented and observed.

First, language learners should be aware of the differences in the real world. Currently, no fixed national barriers can be found easily in many aspects of human life. We can understand this reason in a way that the more they know about the diversities in different corners of the world the more success they may achieve in the future. The awareness about the variety of cultures, language (or even just English itself), foods, living styles and so on will prepare their mind and conditions for their learning and their future.

Second, suitable exposure to multiculturalism allows EFL learners to widen their knowledge, experience from their adventure and activate their potentials and reactions in different circumstances. "Multicultural education is highly wondered by many critics, which is considered to be an alternative for the solution and educational problems" (Sengul 2015: 342). This author also emphasizes that the existence of multicultural societies is obvious and its interactions also occur in education. From that aspect, equal learning opportunities are essential for any individual, regardless of gender, social status, or ethnic, racial, and cultural background.

When teachers create suitable learning environments for learners to experience multicultural differences and perspectives from using Skype ${ }^{7}$ in Education ${ }^{8}$ including Mystery Skype and Virtual Skype Trip for young learners, Skype in the classroom for any type of learners and guest speakers for a specific group of learners on different themes and purposes.

"Skype provides a variety of educational opportunities for classrooms. Students can connect with other students, increase their knowledge, and interact with other cultures. In addition, Mystery Skype is

\footnotetext{
${ }^{7}$ Skype is not the only tool in digital environment

${ }^{8} \mathrm{~A}$ new version of Skype - Skype in Education is the advanced application of Skype under Microsoft for educational purposes
} 
both fun and instructive game for learners with different time zone connections with educators, students, and interesting people across the world." ${ }^{\prime 9}$

Third, essential opportunities to expose to multiculturalism in the real-life and even from online conditions would create favorable conditions for the language classrooms to connect with authors, experts, guest speakers, and researchers around the world. Through these connections, the concept of multiculturalism can be embedded naturally in classroom situations.

Regarding the aforementioned reasons, a lot of research has been conducted relevant to multiculturalism from different perspectives about the societies for fewer discriminations, more equalities, and conditions in multicultural education. Similar cases are found related to the use of Skype in the classroom for developing one or some language skills or communication. However, the gap of these studies is that none is found related to the learners' exposure to multiculturalism through the use of Skype. From the reality of the teaching practice in the Mekong Delta of Vietnam, the data from a survey shows that only 8 (approximately 5.6\%) out of 144 participants have used or have been introduced to Skype in the classroom to connect with teachers from other places regardless the purposes of their connections. In a different public poll recently this year to quickly grasp the way how Skype has been used by teachers on social media, forty-seven participants responded to the poll and the distribution of the purposes to use Skype can be found in the following graph. It can be seen that more than half of the population has used Skype for creating a creative and cooperative learning environment that shares some possibilities and common ideas with using it for the exposure to multiculturalism in the focus of this study.

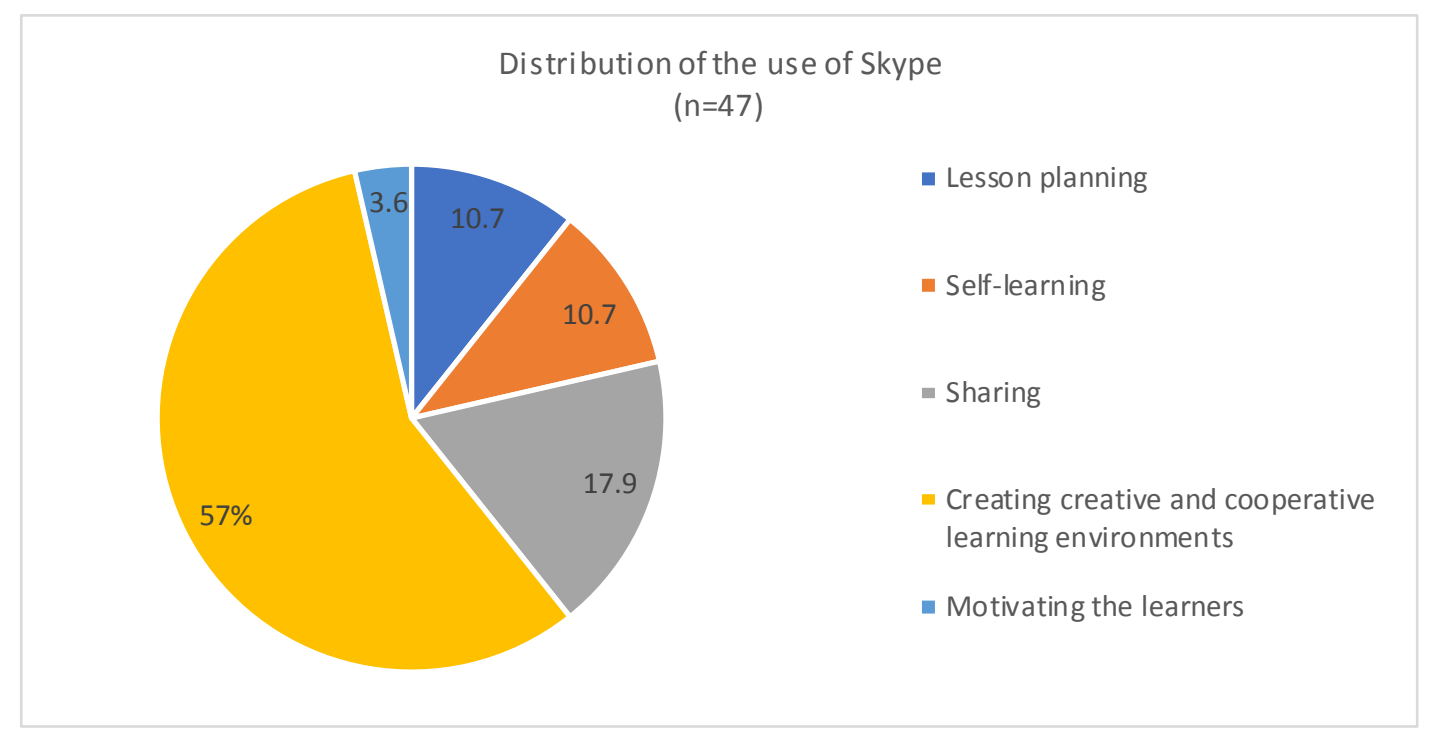

From that, this paper focuses on using Skype in the classroom to promote EFL learners' exposure to multiculturalism from a case study. The study has attempted to address the key points of (1) the motives for bringing different values of culturalism to the learners in the research context, (2) the practices of how Skype in the classroom can be applied for multicultural connections around the world, and (3) the common curiosity about other cultures through the exposure to multicultural classrooms.

\footnotetext{
${ }^{9}$ Online Tools for Teaching and Learning (Unknown Published Date). Skype [Web blog post]. Retrieved from https://blogs.umass.edu/onlinetools/community-centered-tools/skype/
} 


\section{A review of relevant literature}

The key concepts of this study include multiculturalism (1) for the future multicultural societies and (2) in language teaching and learning and (3) digital learning environment and the use of Skype in the classrooms. In these societies of multiculturalism, Smits and Janssenswillen (2019) imply that the teachers in the $21^{\text {st }}$ century including the preparation for future teacher educators should be equipped with experiences and awareness about classroom diversity. The ability to deal with diverse learners in different educational contexts for multicultural teaching should be developed during the process of theoretical transference of culturally responsive education to varying classroom settings. Besides, Sengul (2015) highlights that accommodating all differences in cultures, races, and religions in multiculturalism turns to be more and more important in the current era of globalization. Its objectives aim at preventing potential conflict and chaos. These efforts, when being successful, may lead mankind to a peaceful life and equal rights in a bigger community.

\section{Multiculturalism for the future multicultural societies}

Different perspectives about multiculturalism can be found in Smits and Janssenswillen (2019), Jee (2016), Taylor (2010), Bruna (2009), Gorski (2009), Riley et al. (2004), and Muenstermann (2001). One side focuses on the benefits, rights, and opportunities of minorities in the societies with good preparation for multiculturalism to deal with possible problems and the other side goes for the possibilities of alternating and weakening the host cultures.

In any society, conflicting perceptions about culturalism and multicultural education can be found regarding the possibilities of diminishing the common culture in a host place or the balanced focuses on a democratic position for unity and solidarity. In Taylor (2010 as cited in Sengul 2015: 341), without mutual respecting rationalist, intellectual, political and cultural differences, multicultural societies may witness more potential problems which may be prevented only through meaningful knowledge and interaction of multiculturalism.

For a possible solution, Smits and Janssenswillen (2019: 15) raise the importance of teaching cultural varieties so that learners can be successful in both the existing society and the diverse future which need more possible unfamiliar adjustment and achievement (Gorski 2009: 310).

In Riley et al. (2004), a culturally-diverse society with a monocultural perspective is not appropriate and does not educationally prepare well for the next generations of the current globalization. In a different context of Australia, the manner in which perceived multiculturalism has changed dramatically since 1973. Multiculturalism is connected to the rights and opportunities of minorities (Muenstermann 2001: 93).

From a different perspective, Jee (2016: 244) analyzes how "critical multiculturalism is socially and culturally constructed". Regarding this belief, Kubota (2004: 37) states that while liberal multiculturalism focuses on universal commonality and natural equality among people, critical multiculturalism ... recognizes that social and economic inequality does exist and it critically examines how inequality and injustice are produced and perpetuated in relation to power and privilege.

It is also important to credit the concentration on multiculturalism with the work of Bruna (2009). This author points out five assertions for future multicultural societies as follows:

Assertion 1: all children bring differences to school

Assertion 2: only some of the differences children bring to school are associated with social disparities

Assertion 3: we need to make formal provisions for the disparity-related differences

Assertion 4: to both understand and respond to disparity-related differences, we need to practice from a material theory-of-cumulation standpoint

Assertion 5: practicing in this way means seeing the other as oneself 
With a slightly different concentration, Riley et al. (2004) implement four practices to connect different groups of learners for a better understanding of the world beyond their own community and become aware of global issues.

\section{Multiculturalism in language teaching and learning}

From different practices but similar concepts and goals, the importance of multiculturalism has been recognized in different language and teaching contexts as in Smits and Janssenswillen (2019), Sengul (2015), Milans (2006), Riley et al. (2004), and Gay (2002). They all put an emphasis on the possible successful conditions for future multicultural preparation and the benefits of being knowledgeable with proper interaction with multiculturalism, especially from the classrooms.

Being compatible with Riley et al. (2004), but with a further probable tool for promoting multiculturalism, learners' global-multicultural perspective and knowledge about distant locations can become great opportunities for language development through the use of video-conferencing, including Skype in the classroom. This author emphasizes the benefits of multicultural understanding in language learning through interaction with people in other cultures. In different cultural targeting lessons, students will be more aware of the fact that their understanding of other cultures, perspectives, and reality may be more alike than different.

Sharing similar perspectives, Milans (2006: 63) specifies the multicultural goals of understanding "the differences between the two forms of education including (1) learning teaching ideologies, (2) social practices in the implementation of language teaching methods and (3) interactions in classrooms as a consequence of these methods."

Relatedly, Smits and Janssenswillen share the ideas of developing the curriculum with the combination of "Teaching with Multicultural Competence" and "Teaching in Sociopolitical Context" (2019: 3) with the focus on interculturality and diversity of multi-perspectivity into educational practice. According to Gay (2002: 106), the keys for a successful teaching and learning environment is "using the cultural characteristics, experiences, and perspectives of ethnically diverse students as conduits for teaching them more effectively." In case that the contexts of multiculturalism is not obviously recognized, EFL learners still differ in various religions, languages, family backgrounds, races, and genders.

With the objectives of offering education without differentiation, language instructors should have multicultural competence and awareness as the means of promoting respect towards different cultures and a suitable setting for mutual understanding for multiculturalism (Sengul 2015). According to this researcher, although the world has different emphases on multiculturalism and multicultural education, a classroom with no discrimination may create a peaceful feeling of belongingness. From that sense, bringing multiculturalism to the classrooms that are far away in any corners of the world with the internet and the interactions between learners would build up more values for the practices of language learning and teaching.

Digital learning environment and the use of Skype in the classroom

Digital learning environments enforce communicative and cultural integration. Riley et al. (2004) state that the existing curriculum with extra video-conferencing could be a meaningful and purposeful way to facilitate students' benefits including promoting a global-multicultural perspective, increasing students' knowledge about distant locations, developing problem-solving skills, increasing student motivation, and providing opportunities for language development. In a different way of understanding, the authors emphasize that Skype is a type of video-conferencing that provides the capability to connect students who are separated by great distances, who otherwise would likely never have the opportunity to communicate face-to-face (or screen-to-screen) with one another. Through video-conferencing, learners 
move beyond the confines of their classrooms and transcend geographic boundaries. (Riley et al. 2004: 43)

According to Morgan (2013:197), Skype is a free service for education and allows the users to make video and voice calls using the Internet with the advantage of "teleconference with others even if they live in a remote area". Regardless of the problematic sides of the new technology, no connection, or any drawbacks, Skype creates more awareness about the language differences, various targeting classroom locations, diverse expertise, understandings of cultural contexts, and new learners' interests.

In a different context of Taiwan et al. (2013) conduct an experimental study about the strategy to enhance learners' writing and speaking skills using Skypes and other voice over instant messaging platforms. In different phases, the authors find that the quality of their competence increases on the applications of Facebook and Skype. However, in this study, the effectiveness of Skype shows a negative correlation between learners' learning effects and those who posted more messages in Skype discussion activities. Since this study focused on a different measurement and instant messages on Skype only, the concentration of the current study was on a different aspect of online video connection with other cultural settings or contexts. For that reason, the use of Skype may purposefully influence the effectiveness of any teaching and learning situations, including those for multiculturalism.

Tian \& Wang (2010: 185) clarifies the advantages of using Skype from "its affordability, reliability, ease of use and, more importantly, its pedagogical soundness." Compatible with Riley et al. (2004), this reliable and user-friendly tool supports good quality video and audio transmission in 28 languages for most countries in any corners around the world with Internet availability. In a different practice of Skype, Tian \& Wang (2010) cite the project with the development of speaking skills by pairing learners of Spanish with expert speakers by videoconferencing.

In any effective connections in the classroom, the development of a multicultural understanding with whom they interact can be found in both students and the teacher (Cifuentes \& Murphy 2000). In a special and successful digital learning environment, a clearer understanding of various global perspectives can be learned and acquired naturally and interactively. These authors also highlight the values of learning to communicate across different cultures and the possibilities to introduce cultural practices and distinctions to the connected contexts. The possibility of using Skype basically for distance learners that itself is actually a limitation for face to face learners; however, Skype can commonly be integrated with one-to-one learning settings too.

\section{Research methodology}

In order to collect data for these main focuses, action research was conducted in the research context with a one-year case study. The researchers have joined the study from the beginning stage for a year with the tendency of bringing more multicultural conditions to the classrooms. The data was mainly collected in the forms of qualitative observations of Skype connections, in-class discussions with the learners before and after the connections, the teacher participant's reflections after every trial-and-error step from Jan $5^{\text {th }}, 2018$ to December $20^{\text {th }}, 2019$, and an interview to confirm and clarify the information related to participant's reflections. The length of the connections is varied from 7 minutes to 45 minutes approximately. Therefore, the limitation of this research includes the size of participants and the selfreported type of data. However, in a quite long process, the qualitative data after collected was framed and analyzed using the new version of Raymond Padilla's unfolding matrix as in Nguyen (2018).

This one-year action research - simply a way to do research (Mcniff et al. 1996) - was implemented with a case study because it needs a process that involves the teacher's epistemology, ideology, and generalization from the past to present experience about teaching, learning, and classroom with new application of technology with Microsoft in Education. The choice of action research for the methodology of a one-year case study would allow the researchers and the teacher to have more understanding, experiences, improving the approach to teaching during the teaching and learning 
process (Kemmis \& McTaggart 1988) and the professional development with ICT in the classroom (Elliot 1991). In this study, the loops of stages include different cycles of action - multicultural connections with observation, participant's reflection, and interview. These actions are repeated for the connections in every month. However, it shows no clear starting points of planning, teaching, self-reflecting and modifying as in the stages of planning, action, observation, and reflection in Bustingorry (2008), in which observation was conducted during the connections with other classrooms through Skype and it was a minor action during the teaching practices.

\section{Findings and discussions}

In a new forum on Facebook which was recently created in 2019 in the research context, there are about 4.700 members across the country and educators from different places in the world. They have joined this secret group for different purposes as (1) learning how to do Skype in education in the classroom from other educators, (2) connecting with classrooms around the world, (3) playing games with classrooms in other places, (4) visiting other places through Skype, and so on. From a similar curiosity at the beginning of 2019, the participant of this study has attempted to use Skype in the classroom with these aforementioned purposes and then to achieve the goal of letting his learners have more exposure to multiculturalism through the Skype connections. As mentioned earlier in the introduction in a public poll on social media, none out of the five purposes that teachers have used Skype in their classroom, none of that directly indicates the use of Skype for promoting learners' exposure to multiculturalism.

From the findings, the 69 extracts have been classified into three different groups of information related to (1) the participant motives to facilitate multiculturalism in EFL learning contexts, (2) the praxis of how Skype could be used for multicultural connections, and (3) the development of learners' common curiosity about other cultures through the exposure to multiculturalism.

The motives for bringing different values of culturalism to the learners

The findings from different coded extracts ${ }^{10}$ are varied regarding the motives for taking more chances to expose to culturalism. From different types of data from researchers' interviews and observation as well as participant's reflection, the consistency for the goal of facilitating learners' exposure to multiculturalism is recognizable.

"After a year of utilizing Skype in the language classroom, my students and I have visited 10 countries with 32 connections for a distance of 232038 miles. We have met and learned a lot about their cultures, the differences, the similarities, and the new way of educational innovation in various places." [ID036]

"In my mind, language learners must understand that the world of English is so much different out there. If they have no awareness of the diverse cultures, no learning or changing will be made for their future." [RJ007]

"On the first connection, the teacher shared that he registered the schedule to have the first Mystery Skype with a group of high school international students from Poland. Some problems with the connections could not stop both the teacher's and learners' eagerness of meeting new friends and learn about their cultures like in the real-life through an Ipad screen." [0J011]

"My students can't wait for the next connection next week with an American writer. I know that reading book is not their favorite activity and the first connection was not very

\footnotetext{
10 The extracts were first selected and coded in the form of [[I - interview/O - observation /R- reflection] [Month - the first letter of the month, except for j-June, jx- July, m-may, a- August] [3 digit numbers - ordinal numbers of the extracted codes] and then classified one more time into three groups of findings related to the motives, the practices, and the curiosities.
} 
smoothly organized, but I just want to do my best for my students to meet people from different cultures." [IF004]

Not only the teacher-participant but also the learners are motivated a lot after the first partly successful connection with a country far away from the research context.

"I learned a lesson today. When my students can speak English, it does not mean that they are ready to speak with foreigners, even using an iPad. It was good that both sides are tolerant and understand the situations well. Eliciting questions are really good to activate or lead my students' responses. I will continue with the next connections." [RF017]

"Most learners are shy when they need to say something. In this connection, some good students volunteered to move to the front and the teacher organized students sitting close to each other in 2 rows so that the screen can cover all their faces." [OF006]

"Skype is not simply a type of connection for multiculturalism. We can feel that the teacher becomes more skillful in his technological skills. He can transfer the screen of the Skype connection to the big TV screen in the classroom. He is very happy with that and this Skype turns to be more successful than the previous ones." [OM013]

"As long as my students want to try something new, I will continue my ways. More Skype may take times and it was not well on the first day, but with the same will, we will do it together." [IF005]

As educators or language teachers, when there is something good for the learners in limited conditions, the logical requests anyone to have a choice or to give up. Any instructors had better try it at all costs. Similarly, the participant in this study has some unique motives for utilizing Skype in his classrooms in the long run.

"I use Skype because it allows my learners to access different types of accents, and a variety of cultures. That is enough and better than telling them a thousand times about the diversities in the world. Even when I show them videos about different accents of English, they just laugh. They think of English spoken by the native speakers in Britain, USA, Canada, Australia..., not the lingua franca." [IM022]

"The important things in learning a language should be linked to the knowledge and experience of different cultures. However, it is hard to find a chance to meet people from other countries if you are not in big cities. What my students need is real-time conversations with speakers of English from different contexts, a type of free education for the future of globalization." [IM058]

"It will be very interesting and cool when your students might have some problems in understanding the conversations from the other sides of the world for their first time, but you do not. It is just simple that you learn the language in a longer period of time and you have more friends from different contexts and you have spoken English to different accents before. Learners will pay attention to that sense and decide on their learning routes or what they need for a new future." [IM025]

The values of exposure to multiculturalism would be very significant only if the language learners and their teachers have some recognitions, like the participant in this study. Although not much research has been done regarding the use of Skype for facilitating more exposure to the diverse cultural contexts, the compatible perspective with this study can be found in Smits and Janssenswillen (2019) and Bruna (2009) because teaching cultural varieties is very important to the success of learners. As from the extract IM022, students laugh when they have conversations with students or teachers from other contexts and cannot understand them. Their accents may be different and it may not be related to respect or similar issues. However, it should be obtained as a problem without mutual respecting rationalist, intellectual, political and cultural differences in multicultural contexts as compatible with Sengul (2015). 
The practices of Skype for multicultural connections around the world

As quoted in the extract of ID036, the participant has made 32 connections to educators and classrooms in 10 countries including Japan, Poland, the USA, India, Spain, Vietnam, Argentina, Norway, Russia, and Canada. The findings indicate that Skype provides the counterparts of the connections more chances to have more awareness about the world and its multicultural aspects.

"I have to admit that Skype in Education being utilized in the classrooms is really helpful for different purposes. However, when my students realize that their English is so much different from what they have learned from the textbooks. They have some types of awareness for their learning autonomy. They may have some questions, they may want to research that, and they may also have new goals for their learning. The same English differs in various cultures and in itself." [Im031]

In most connections, both learners and teachers have great opportunities to study and possibly join global projects like "No Hunger" and "Let's practice English together". However, the findings show that students in this context are still not interested in actively participating in these projects for their extra curriculum. The values from practices of Skype have been reduced accordingly.

"During the first time of having Skype about the project of No Hunger, students seem to be out of track. The language is somehow different from more standardized accents so they lost the information. In the repeated version of a different connection, the project manager of No Hunger enthusiastically introduces it again with more time for ways to connect, guides after the Skype and actions. However, no further interests or actions have been registered or recognized from the participant context." [OA018]

Sitting in a classroom but learners can travel with the connections on the other side of the world is really a great adventure. Both the participant and learners in the research context have experienced real historical places or famous sightseeing through a screen. Skype through Virtual Field Trip (VFT) not only gives learners more direct motions and views but also creates a desire to commit similar VFT for other viewers in different connections.

"One of my impressions during my Skyping goal is that my learners have developed their eagerness and willingness to share their cultures with the world too. You can see how my students and I learn through Skype and the culture of sharing and understanding others in any place. Learners enjoyed the tour through the World behind the Wall from an educator from India. Although I am not sure that they understand the core meanings of the activity, they start to brainstorm things they can do or places they can show people when they connect with them again." [Im021]

"I have never tried or developed any ideas to show anyone through Skype about places I live, work, or visit. I am always worried about the quality of data without a strong Wi-Fi connection. However, in a connection with a changing in the place of learning from a classroom to a tourist island, I connected my class in a tourist place with an educator from Gdansk. We were in the house of Coconut and everything is made by coconut trees. At that time, I just thought that it is something unique in my place with different kinds of tropical fruits on the trees. Different groups of my students took my iPad with that connection to move around the places and introduced what they know in English." [Rj038]

Of all connections, it is a process of teaching, learning, and professional development for the participant. In every connection and every new form of Skype, the participant shows his ability to learn from trial and error and his enthusiastic attitudes to sharing and bringing multicultural conditions to his classrooms. All in all, the findings are compatible with Milans (2006) for a new chance of practices and different forms of interactions, in this case, the classroom is not inside four walls with the facilities and learning becomes more productive with more output directly through the Skype connections. In addition, this study shares the common values with Morgan (2013) when the connection with the 
available Internet, this free service allows the learners to have VFT under the sense and the advantage of using teleconference in a remote area. Skype in this practice really facilitates learning and sharing from different cultures and perspectives. Similar to Morgan (2013), Yen, Houb \& Changa (2013) also share the same goals, no matter with and without the facilitation of multiculturalism, the chances to enhance speaking skills using Skypes and other platforms.

The development of cultural curiosities through exposure to multicultural classrooms

Not racism, but the different color, voice, race, language, learning majors, food, fruits, vehicles, housing, education... all become the target of new phases for asking questions. Students become curious about cultural differences. The development of cultural curiosity may trigger their desire to learn and the exposure to multicultural classrooms would really be a surprise for the fast movement of the globalization.

"I am sure that students understand why in Russia students are diverse and each of them is usually from different countries including Vietnam. However, I do not think that they agree with the phenomenon of having individuals from different contexts in their place. They cannot see and understand that from their classrooms and reality. I believe that they are curious because they care about the possibility of having the same conditions as in European and ASEAN territories." [ljx042]

"At the end of most Mystery Skype, students usually ask why friends on the other side of the connection know that they are Vietnamese. In most guests-speaking Skype, they always want to know more about the cultures of the speakers - the place they live, the language they speak, the food they eat, the clothes they wear, the education they are in, and what similarity or difference would be. It seems that the participant has a well- prepared lesson so most curious quests have been responded." [Oa033]

If not separating the art of teaching in general to language teaching, one of the most important components of learning must be "curiosity" and "the desire to understand" which would facilitate the learners' learning process and autonomy (Rancière, 1991). In most teaching cases, developing curiosity for students is important. This viewpoint commonly shares the same ideology with Nguyen (2015) about the core of learning and the roles to activate learners' curiosity and learning desire (Rancière, 1991). When learners become aware of their curiosity in learning about multiculturalism, notions of cultural difference should be truly recognized as part of the essence of the human being in which the values of different perspectives should be enhanced for learners' process of significant learning (Nguyen, 2017) ${ }^{11}$

\section{Conclusions}

Studying in recent days has not bound in the four walls of a classroom anymore. The development of technology has provided learners with favorable conditions for acquiring the necessary knowledge and skills, especially learning about the world in the most practical way. The awareness and knowledge of multiculturalism which helps contribute to the integration capabilities of one have become the priority of any education in such a flat world today. Regarding this, the application of Skype as one of the ICT in education demonstrates its effectiveness in promoting EFL learners' exposure to multiculturalism with the cheapest price from this case study should be encouraged for its use worldwide.

Teachers, one of the educational stakeholders are believed to play an active role in inspiring their learners to discover the other cultures so that they can adapt well to social situations related to multiculturalism in the era of the coexistence of diverse cultures nowadays. Learning, discovering places and sharing with each other from different countries regardless of race, religion, complexion, and cultures via Skype is worth considering for applying in an EFL classroom for learners' development of 
multiculturalism. In other words, with the knowledge of multiculturalism, a learner can be prepared well for his later life or career.

\section{Limitations}

This study was conducted with a case study in only one year. The values of its influences may not be fully observed and analyzed in such a short time to generalize for possible lessons regarding the implementations of Skype for multiculturalism. For the data, it should be exploited deeper into the beneath layers of information with more cases and entries.

\section{Recommendations and suggestions for future research}

Despite such limitations, the study should focus on a broader aspect of distance learning regarding multiculturalism with a proper comparison among different digital tools and settings. More cases should be investigated from different contexts for possible diversity. More studies should be conducted about the users of Skype or other digital tools for teaching and learning not only in multiculturalism in such limitations of direct contacts but also in other learning demands.

\section{References}

Bruna, R. K. (2009). Materializing Multiculturalism: Deconstruction and Cumulation in Teaching Language, Culture, and (Non) Identity Reflections on Roth and Kellogg. Mind, Culture, and Activity, 16 (2), 183-190, DOI: 10.1080/10749030802590606.

Bustingorry, S. O. (2008). Towards teachers' professional autonomy through action research. Educational Action Research, 16 (3), 407-420.

Cifuentes, L. \& Murphy, K. L. (2000). Images of Texan and Mexican cultures shared in a telecommunications partnership. Distance Education, 21 (2), 300-322. https://doi.org/10.1080/0158791000210207.

Elliot, J. (1991). Action research for educational change. Open University Press. USA: Buckingham.

Gay, G. (2002). Preparing for culturally responsive teaching. Journal of Teacher Education, 53 (2), 106-116.

Gorski, P. C. (2009). What we're teaching teachers: An analysis of multicultural teacher education coursework syllabi. Teacher and Teacher Education, 25, 309-318. doi: 10.1016/j.tate.2008.07.008.

Jee, Y. (2016). Critical perspectives of world Englishes on EFL teachers' identity and employment in Korea: an autoethnography. Multicultural Education Review, 8 (4), 240-252.

Kemmis, S. \& McTaggart, R. (1988). The Action Research Planner (3rd ed.). Geelong, Australia: Deakin University Press.

Kubota, R. (2004). Critical multiculturalism and second language education, in: B. Norton \& K. Toohey (Eds.), Critical pedagogies and language learning, Cambridge: Cambridge University Press, 30-52.

McNiff, J., Lomax, P. \& Whitehead, J. (1996). You and your action research project. Routledge: New York.

Milans, P. M. (2006) Spanish Education and Chinese Immigrants in a New Multicultural Context: Cross-cultural and Interactive Perspectives in the Study of Language Teaching Methods. Journal of Multicultural Discourses, 1 (1), 6085, doi: 10.1080/10382040608668532.

Morgan, H. (2013). Technology in the Classroom: Using Skype for Exciting Projects. Childhood Education, 89 (3), 197-199, doi: 10.1080/00094056.2013.793076.

Muenstermann, I. (2001). Implementing Multiculturalism within the Context of Australian society: South Australia's school for the German language. Intercultural Education, 12 (1), 93-107, doi: 10.1080/14675980120033993.

Nguyễn, D. K. (2018). New Application of Raymond Padilla's Unfolding Matrix in Framing Qualitative Data and the Follow-up Activities for Educational Research. Journal of International Qualitative Methods, 17 (1). Available at http://journals.sagepub.com/doi/metrics/10.1177/1609406918786820

Nguyễn, D. K. (2017). Action Research about Students' Significant Learning in Higher Education: one of the Valuable Tools for Pedagogical Professional Development. VNU Journal of Science: Educational research, 33 (2), 39-51, doi:10.25073/2588-1159/vnuer.4077.

Online Tools for Teaching and Learning (Unknown Published Date). Skype [Web blog post]. Retrieved from https://blogs.umass.edu/onlinetools/community-centered-tools/skype/

Rancière, J. (1991). The Ignorant Schoolmaster. Stanford University Press. California. 
Riley, J., Garza-Reyna, G., Muñoz, A., Lawrence, G., Shelton, M. \& Rojas-Paz, A. (2019). Video-Conferencing to Promote Global Awareness, Kappa Delta Pi Record, 55 (1), 42-45, doi: 10.1080/00228958.2019.1549443.

Sengul, M. (2015). Multicultural Competence of Instructors in Turkish Language Teaching Centers. The Anthropologist, 21 (1-2), 341-349, doi: 10.1080/09720073.2015.11891823.

Smits, F. H. T. \& Janssenswillen, P. (2019). Multicultural teacher education: a cross-case exploration of pre-service language teachers' approach to ethnic diversity. International Journal of Qualitative Studies in Education, 33 (4), 421-445, doi: 10.1080/09518398.2019.1681536.

Tian, J. \& Wang, Y. (2010) Taking language learning outside the classroom: learners' perspectives of eTandem learning via Skype. Innovation in Language Learning and Teaching, 4 (3), 181-197, doi: 10.1080/17501229.2010.513443.

Yen, Y. C., Houb, H. T. \& Changa, E. K. (2013). Applying role-playing strategy to enhance learners' writing and speaking skills in EFL courses using Facebook and Skype as learning tools: a case study in Taiwan. Computer Assisted Language Learning, 28 (5), 383-406, doi: 10.1080/09588221.2013.839568. 